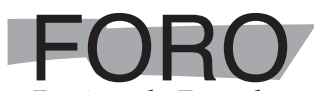

Revista de Derecho

\title{
El procedimiento de solicitud de adecuación de los datos de conformidad con la identidad de género. Reflexiones desde el derecho fundamental a la protección de datos
}

The procedure for requesting adequacy of the data in conformity with gender identity. Considerations from the fundamental right to data protection

\section{Luis Ordóñez Pineda}

Docente de la Universidad Técnica Particular de Loja, Ecuador loordonez@utpl.edu.ec

ORCID: 0000-0002-0262-2212

DOI: https://doi.org/10.32719/26312484.2019.32.10

Fecha de recepción: 30 de abril de 2019

Fecha de aceptación: 25 de septiembre de 2019

Licencia Creative Commons

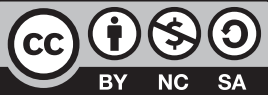




\section{RESUMEN}

En la actualidad el derecho fundamental a la protección de datos personales se considera como un instituto de garantía de otros derechos fundamentales. Asimismo, con referencia a la Opinión Consultiva OC-24/17 de la Corte Interamericana de Derechos Humanos, el derecho a la identidad de género comparte con este derecho fundamental una serie de principios y garantías que desde el ámbito constitucional fortalecen el respeto de la igualdad y no discriminación. Sobre esta base, este artículo trata de poner de manifiesto la importancia de establecer medidas responsables y pertinentes que aseguren que el procedimiento de solicitud de adecuación de los datos, de conformidad con la identidad de género, corresponda con la protección de datos sensibles o especialmente protegidos.

Palabras Clave: Hábeas data. Datos Personales. Datos sensibles. Derechos fundamentales. Identidad de género.

\section{ABSTRACT}

Nowadays, the fundamental right to the protection of personal data is considered as an institution guaranteeing other fundamental rights. Moreover, with respect to Advisory Opinion OC-24/17 of the Inter-American Court of Human Rights, the right to gender identity shares with this fundamental right a series of principles and guarantees that, from the constitutional point of view, strengthen respect of the equality and non-discrimination. Under these considerations, this article tries to highlight the importance of establishing accountability and pertinent measures that guarantee that the procedure for requesting the adaptation of the data in accordance with the gender identity corresponds to the protection of sensitive or specially protected data.

Keywords: Hábeas data. Personal Data. Sensitive Data. Fundamental Rights. Gender Identity.

\section{INTRODUCCIÓN}

obre la base del respeto de la dignidad humana y de los límites que se imponen al $\checkmark$ poder público y privado, la aplicabilidad de los derechos fundamentales como una regla de decisión forma parte de las características que desarrollan la construcción de un Estado constitucional de derechos.

Así pues, cualquiera sea el fundamento filosófico de la inherencia de los derechos humanos a la persona, el reconocimiento de la misma por el poder y haber quedado plasmada en instrumentos legales de protección en el ámbito doméstico y en el in- 
ternacional han sido el producto de un sostenido desarrollo histórico, dentro del cual las ideas, el sufrimiento de los pueblos, la movilización de la opinión pública y una determinación universal de la lucha por la dignidad humana han ido forzando la voluntad política necesaria para consolidar una gran conquista de la humanidad, como es el reconocimiento universal de que toda persona tiene derechos por el mero hecho de serlo. ${ }^{1}$

El actual Estado constitucional de derechos y justicia ecuatoriano se sostiene sobre un sistema jurídico que respeta, en todas sus dimensiones, la dignidad de las personas y las colectividades. No solamente en el respeto de las garantías normativas y jurisdiccionales previstas en la Constitución, sino también en el reconocimiento de convenios internacionales y de decisiones de organismos del sistema interamericano o universal para la protección de derechos humanos. ${ }^{2}$

A diferencia del marco europeo, aun cuando se han aprobado algunos instrumentos comunitarios, en la región se evidencia un carente desarrollo de normativa transnacional que posibilite la integración latinoamericana en términos de armonizar jurídicamente la protección y tutela del instituto de garantías que comprende el derecho fundamental a la protección de datos personales. ${ }^{3}$ En todo caso, conviene resaltar que la Opinión Consultiva OC-24/17de la Corte Interamericana de Derechos Humanos, en adelante OC-CIDH, significa un avance no solamente en derechos relativos a la

1. Pedro Nikken, "Sobre el concepto de Derechos Humanos", en Instituto Interamericano de Derechos Humanos, Seminario de Derechos Humanos (San José: IIDH, 1997), 23.

2. La Corte Constitucional explica que por normas "ecuatorianas" se entienden "aquellas que tienen vigencia y fuerza obligatoria en jurisdicción ecuatoriana, incluyendo aquellas establecidas en tratados y convenios internacionales, decisiones de organismos del sistema interamericano o universal de protección de derechos humanos, u otras fuentes de derecho, reconocidas en la Constitución de la República como parte del ordenamiento jurídico del Ecuador". Cfr. Resolución de la Corte Constitucional 184-18-SEP-CC, Caso n. ${ }^{\circ}$ 1692-12-EP.

3. Sobre la necesidad de promover un marco latinoamericano, hemos señalado que el informe sobre Privacidad y Protección de Datos Personales de la OEA en 2015 (Guía Legislativa para los Estados Miembros fundamentada en Doce Principios) "debe desembocar en la implementación de una Ley o Reglamento Interamericano que permita desarrollar en el ámbito regional y régimen jurídico interno de sus Estados Miembros un marco equilibrado y homogéneo que asegurare, en la práctica, su protección integral". Cfr. Luis Ordóñez Pineda, "La protección de datos personales en los estados que conforman la Comunidad Andina: estudio comparado y precisiones para un modelo interamericano de integración", Foro: Revista de Derecho, . $^{\circ} 27$ (2018). En todo caso, si bien en el contexto latinoamericano aún no se ha desarrollado una Ley Modelo, la REDIPD concretó en 2017 la aprobación de otro instrumento regional importante denominado "Estándares de Protección de Datos Personales para los Estados Iberoamericanos". Este instrumento, puede considerarse como un modelo por cuanto se exponen disposiciones relativas a los principios; derechos y obligaciones; ejercicio de los derechos arco; medidas proactivas; autoridades de control; $\mathrm{y}$, reclamaciones y sanciones. 
identidad de género, sino que además representa un importante precedente jurídico internacional en materia de protección de datos personales.

Así, en primer término, la OC-CIDH señala que:

La Convención contiene una cláusula universal de protección de la dignidad, cuyo basamento se erige tanto en el principio de la autonomía de la persona como en la idea de que todas las personas deben ser tratados como iguales, en tanto son fines en sí mismos según sus intenciones, voluntad y propias decisiones de vida. Además, la Convención Americana también reconoce la inviolabilidad de la vida privada y familiar, entre otras esferas protegidas. Este ámbito de la vida privada de las personas, ha sostenido la Corte, se caracteriza por ser un espacio de libertad exento e inmune a las injerencias abusivas o arbitrarias por parte de terceros o de la autoridad pública. ${ }^{4}$

Considerando que el derecho a la protección de datos personales tiene el carácter de autónomo e independiente respecto a otros derechos fundamentales -el derecho a la intimidad, desarrollo de la personalidad e identidad, por ejemplo-, debe recordarse que todos ellos comparten dentro de su instituto de garantía el respeto hacia la dignidad humana en todas sus dimensiones. Como señala la Corte Constitucional del Ecuador:

El derecho a la identidad ha sido determinado por la Corte Constitucional como inherente a la personalidad de cada individuo y esencia misma de la dignidad humana. De igual forma, implica el reconocimiento de las facultades de cada sujeto, que a su vez se traducen en las características individuales de su condición de persona. Por tal motivo, el efectivo goce del derecho a la identidad es un prerrequisito para la materialización de otros, pues a través del mismo cada ente se relaciona jurídica y socialmente con el Estado y entorno. ${ }^{5}$

Precisamente, el derecho a la protección de datos personales emerge del respeto a la dignidad como base fundamental para la protección, entre otros derechos, de la intimidad de la información personal, del nombre, de la identidad y de la propia imagen frente a los abusos que puede ejercerse en su tratamiento dentro del ámbito público y/o privado. En todo caso, considerado como un instituto de garantía de otros derechos, "esta relación del derecho a la protección de datos con el resto de derechos fundamentales fortalece su vinculación con la dignidad de la persona". ${ }^{6}$ Además, como señala la OC-CIDH, la protección del derecho a la vida privada "no se limita al

4. Cfr. Opinión Consultiva OC-24/17, párr. 86.

5. Cfr. Resolución de la Corte Constitucional 184-18-SEP-CC, Caso n. ${ }^{\circ}$ 1692-12-EP.

6. Antonio Troncoso, La protección de datos personales: en busca del equilibrio (Valencia: Tirant lo Blanch, 2010), 75. 
derecho a la privacidad, pues abarca una serie de factores relacionados con la dignidad de la persona, incluyendo, por ejemplo, la capacidad para desarrollar su propia personalidad, aspiraciones, determinar su identidad y definir sus relaciones personales".7

Desde esta perspectiva, el derecho a la protección de datos supone que la persona sea tratada conforme a su ser. Implica una condición que limita el ejercicio del poder público y privado a partir del respeto de la dignidad personal. En suma, pretende concretar en beneficio de los ciudadanos - no como un ente aislado, sino como un ser social que vive en comunidad-seguridad jurídica como una condición necesaria para el libre desarrollo de la personalidad y determinación de su identidad. ${ }^{8}$

Como sabemos, en Ecuador la protección de datos personales goza de reconocimiento constitucional. Naturalmente, junto a la garantía de hábeas data constituyen mecanismos de protección y tutela de los bienes jurídicos que comprende el derecho a la autodeterminación informativa. ${ }^{9}$ No obstante, a pesar de la inexistencia de una ley general que desarrolle el contenido del derecho a la protección de datos, su reconocimiento como un derecho de libertad (art. 66.19) y como una garantía jurisdiccional (art. 92) es esencial toda vez que dentro del Estado constitucional de derechos, la justiciabilidad de las libertades reconocidas en la Constitución exige "la prevalencia de su normativa y la obligación de satisfacción de sus postulados, pues en base a ellos se sustenta el carácter mismo de un Estado constitucional". ${ }^{10}$

Con estos antecedentes, tomando en cuenta que la Constitución precisa la protección de los derechos sobre la base de la dignidad humana y aplicación directa e inmediata de estos, ${ }^{11}$ dentro del modelo neoconstitucional tiene pleno sentido asumir que el

7. Cfr. Opinión Consultiva OC-24/17, párr. 87.

8. Al respecto, la Corte Constitucional llama a que las entidades públicas y privadas deben priorizar "el principio de igualdad y no discriminación en la adopción de medidas legislativas, administrativas, así como en el diseño de políticas públicas. Adicionalmente, la Corte Constitucional recuerda la obligación que adquieren los servidores públicos, en ejercicio de sus funciones de aplicar en forma directa los derechos constitucionales sin que se pueda invocar la falta de norma para maximizar su materialización". Cfr. Resolución de la Corte Constitucional 184-18-SEP-CC, Caso n. ${ }^{\circ}$ 1692-12-EP.

9. En el caso del Ecuador el derecho a la protección de datos personales se reconoce como un derecho de libertad (art. 66.19) "que incluye el acceso y la decisión sobre información y datos de este carácter, así como su correspondiente protección"; y, como una garantía jurisdiccional (art. 92) por la cual el titular de los datos personales "tendrá derecho a conocer el uso que se haga de ellos, su finalidad, el origen y destino de información personal y el tiempo de vigencia del archivo o banco de datos". Además, respecto a los datos especialmente protegidos, la garantía jurisdiccional de hábeas data señala que "en el caso de datos sensibles, cuyo archivo deberá estar autorizado por la ley o por la persona titular, se exigirá la adopción de las medidas de seguridad necesarias".

10. Cfr. Resolución de la Corte Constitucional 184-18-SEP-CC, Caso n. ${ }^{\circ} 1692-12-E P$.

11. El Preámbulo de la Constitución de la República del Ecuador refiere la fundamentación del Estado Constitucional de Derechos sobre "Una sociedad que respeta, en todas sus dimensiones, la dignidad de las personas y las colectividades". 
derecho fundamental a la protección de datos emerge tanto del respeto de la dignidad personal como del reconocimiento de un conjunto de derechos que se le atribuyen como instituto de garantía. Sobre esta base, este estudio tiene como objetivos examinar el efecto vinculante de la OC-CIDH en lo relativo a los datos sobre la identidad de género, $y$, además, valorar la aplicabilidad del derecho a la protección de datos a través de las garantías a la igualdad y no discriminación.

\section{El CONTENIDO DEL DERECHO FUNDAMENTAL A LA PROTECCIÓN DE DATOS PERSONALES: LA GARANTÍA DE LOS DATOS RELATIVOS A LA IDENTIDAD DE GÉNERO}

Los cambios sociales y tecnológicos llevaron a instituir sobre este derecho varias denominaciones que pretenden desarrollar no solamente su fundamento sino también el instituto de garantía que comprende. Puede decirse que "la modernidad no solo ha significado el más radical y antes insoñado salto tecnológico y científico de género humano, sino la consolidación de valores nuevos, y el derrumbe de otros". ${ }^{12}$ Desde nuestra perspectiva, el acceso a las tecnologías es una de las características y prioridades de la sociedad moderna. No obstante, se han desvalorizado los riesgos que suponen la sobreexposición de la persona y de su información personal.

Por ello, particular importancia tiene el estudio de la naturaleza de este derecho fundamental, bien, frente al desarrollo de las tecnologías, bien, a partir de los cambios sociales.

En primer término, el derecho a la protección de datos se fundamenta en que "quien trata datos personales trata datos ajenos, no propios, que debe utilizar con estricto respeto a los derechos del interesado. Esta construcción nos reconduce al respeto a la dignidad de la persona, base fundamental de la protección de datos". ${ }^{13}$ Así, a partir del fenómeno tecnológico, a juicio de la OC-CIDH:

El sistema jurídico, debe evolucionar a la par de la sociedad y no puede desconocer los cambios que en esta se operan, so pena de tornarse ineficaz. En este orden de ideas, respecto a los derechos humanos, la ley debe mantener vigentes el alcance de las garantías y libertades reconocidas por la Convención y por el derecho interno. Así, corresponde a la ley, regular nuevas maneras de ejercicio de los derechos humanos, estrechamente ligadas a

12. Nikken, "Sobre el concepto de Derechos Humanos", 46.

13. Pablo Lucas Murillo de la Cueva y José Luis Piñar Mañas, El derecho a la autodeterminación informativa (Madrid-México: Fontamara, 2011), 102. 
los avances y desarrollos tecnológicos [...] Un ejemplo de ello sería el alcance de la libertad de expresión y el habeas data los cuales no eran imaginables hace 50 o 100 años atrás. ${ }^{14}$

Ahora bien, frente a los cambios sociales, el derecho a la protección de datos implica un límite en el tratamiento de la información, principalmente, sobre aquella que la doctrina considera como "sensibles" o "especialmente protegida", y que hacen referencia a "aspectos más privados de la personalidad, como por ejemplo las relativas a su origen racial o étnico, a las opiniones políticas, a las convicciones religiosas o filosóficas, a la salud y a la sexualidad". ${ }^{15} \mathrm{Al}$ respecto, la OC-CIDH agrega que:

En relación con este tema, el Comité Jurídico Interamericano, indicó en su Informe sobre Privacidad y Protección de Datos Personales, que "[a] lgunos tipos de datos personales, teniendo en cuenta su sensibilidad en contextos particulares, son especialmente susceptibles de causar daños considerables a las personas si se hace mal uso de ellos. Los controladores de datos deberían adoptar medidas de privacidad y de seguridad que sean acordes con la sensibilidad de los datos y su capacidad de hacer daño a los individuos sujetos de la información. ${ }^{16}$

Tomando en cuenta que un dato personal constituye cualquier información concerniente a una persona que la identifique o la puede hacer identificable, este derecho fundamental se orienta a garantizar que el tratamiento de información sensible (relativa a su identidad sexual o de género, por ejemplo) se haga bajo un régimen de principios como el de secreto, de seguridad y de confidencialidad. Naturalmente, como se verá más adelante, el objeto de estos principios es impedir que la persona sea objeto de actos discriminatorios, $\mathrm{y}$, así también, demandar en el ámbito público y privado niveles adecuados de protección.

Como expone la OC-CIDH, frente a datos que se desprenden de la personalidad y que pueden acarrear algún tipo de discriminación:

Es ineludible que el Estado y la sociedad, respeten y garanticen la individualidad de cada una de ellas, así como el derecho a ser tratado de conformidad con los aspectos esenciales de su personalidad, sin otras limitaciones que las que imponen los derechos de las demás personas. Es por ello que el afianzamiento de la individualidad de la persona ante el Estado y ante la sociedad, se traduce por su facultad legítima de establecer la exteriorización de su modo de ser, de acuerdo con sus más íntimas convicciones. Del mismo modo, uno de los componentes esenciales de todo plan de vida y de la individualización de las personas es precisamente la identidad de género y sexual. ${ }^{17}$

14. Cfr. Opinión Consultiva OC-24/17, Voto concurrente del juez Humberto Antonio Sierra Porto.

15. Ramón Oró Badia, La protección de datos (Barcelona: Editorial UOC, 2015), 54.

16. Cfr. Opinión Consultiva OC-24/17, párr. 136.

17. Ibíd., párr. 91. 
Si bien en nuestro país uno de los principios constitucionales que rige el ejercicio de los derechos fundamentales (art. 11.8) establece que "el Estado generará y garantizará las condiciones necesarias para su pleno reconocimiento y ejercicio", no debe pasar por alto que es deber de todos los ecuatorianos (art. 83.14) "respetar y reconocer las diferencias étnicas, nacionales, sociales, generacionales, de género, y la orientación e identidad sexual". ${ }^{18}$ En todo caso, desde el reconocimiento constitucional a la protección de datos como un derecho fundamental que protege otras libertades, hasta la aplicación de instrumentos internacionales (la OC-CIDH, por ejemplo), el aseguramiento del derecho a la igualdad y a la no discriminación en el tratamiento de datos relativos a la identidad de género representa uno de los principales desafíos jurídicos a que la administración pública y particulares nos enfrentamos en la actualidad.

Si bien, a juicio de la OC-CIDH, el derecho a la identidad se desprende "del reconocimiento del libre desarrollo de la personalidad y del derecho a la vida privada"; que, "posee también un valor instrumental para el ejercicio de determinados derechos"; y que, al desarrollar principios para la no discriminación, su reconocimiento implica protección "contra la violencia, tortura malos tratos, derecho a la salud, a la educación, empleo, vivienda, acceso a la seguridad social, así como el derecho a la libertad de expresión, y de asociación", puede decirse que la identidad se considera como un dato especialmente protegido que -derivado del reconocimiento del libre desarrollo de la personalidad y del derecho a la vida privada- requiere de medidas especiales de seguridad con el objeto de asegurar la igualdad y la no discriminación. ${ }^{19}$

De ahí que, con el reconocimiento de los derechos a la identidad personal, sexual y de género "se busca lograr que cada persona posea un signo distintivo y singular fren-

18. Al respecto, un precedente importante sentó la Corte Constitucional del Ecuador en el caso emblemático denominado "Satya". Así, con relación al tratamiento de información sensible relativa a la identidad, la Corte advirtió que "el Registro Civil debió inscribir los datos relativos a su identidad, incluidos los de la procedencia familiar, conforme su interés superior lo exigía, pues el reconocimiento legal de la relación filial de una persona es parte fundamental de la personalidad de cada sujeto, sin el cual queda expuesto a una situación gravosa que atenta contra sus derechos. El acto de inscripción no implica un escrutinio potestativo de los datos que a discrecionalidad de la autoridad pública considere como registrables o no; dado que el efecto de registro de nacimiento no solo implica que el Estado toma conocimiento de la existencia de una persona, sino que implica el vínculo jurídico por el cual la persona se ve reconocida de la calidad de nacional, y a través de ello puede ejercer plenamente sus derechos y obligaciones". Cfr. Resolución de la Corte Constitucional 184-18-SEP-CC, Caso n. ${ }^{\circ}$ 1692-12-EP. Reforzando el criterio de la Corte, la OCCIDH señala que "la privación del derecho a la identidad o las carencias legales en la legislación interna para la realización del mismo, colocan a las personas en situaciones que dificultan o impiden el goce o el acceso a los derechos fundamentales, creándose así diferencias de tratamiento y oportunidades que afectan los principios de igualdad ante la ley y de no discriminación, además de ser un obstáculo frente al derecho que tiene toda persona al reconocimiento pleno de su personalidad jurídica". Cfr. Opinión Consultiva OC24/17, párr. 99.

19. Cfr. Opinión Consultiva OC-24/17, párr. 101. 
te a los demás, con el cual pueda identificarse y reconocerse como tal", ${ }^{20}$ esta misma resolución destaca que, como consecuencia de lo anterior:

La falta de acceso al reconocimiento a la identidad de género constituye un factor determinante para que se sigan reforzando los actos de discriminación en su contra, y también puede erigirse en un obstáculo importante para el goce pleno de todos los derechos reconocidos por el derecho internacional, tales como el derecho a una vida digna, el derecho de circulación, a la libertad de expresión, los derechos civiles y políticos, el derecho a la integridad personal, a la salud, a la educación, y a todos los demás derechos. ${ }^{21}$

En este contexto, el hábeas data se manifiesta como garantía que desarrolla el contenido del derecho a la protección de datos, y por la cual se concretan una serie de" derechos y deberes que operan en el marco objetivo ofrecido por los principios de calidad de los datos". ${ }^{22}$ Entre sus objetivos están, por un lado, tutelar el derecho de acceso, rectificación, cancelación y oposición en el tratamiento de la información personal; y, por otro, garantizar que el accionante conozca qué tecnologías se usan para almacenar la información y así también qué seguridades ofrecen los responsables del tratamiento de la información. ${ }^{23}$ Precisamente, como señala la Corte Constitucional -en adelante CCE- frente al tratamiento de datos sensibles o especialmente protegidos el hábeas data "sirve para proteger al ciudadano en caso de que el Estado o los particulares hagan uso de una información incorrecta, inexacta u obsoleta y que, al difundir tal información, se produzcan discrímenes, calificaciones deshonrosas, etc.". ${ }^{24}$

De lo expuesto, suponiendo que en la sociedad moderna la tipología de datos personales es diversa, es necesario establecer la importancia de la eficacia directa de los derechos frente al tratamiento de la información a efecto de garantizar en la práctica, por ejemplo, derechos relacionados con la identidad de género y desarrollo de la personalidad. Por tanto, como garantía para la igualdad y no discriminación, especial referencia debe hacerse a la categoría de datos personales que se consideran como sensibles o especialmente protegidos.

20. Ibíd., párr. 106.

21. Ibíd.

22. Murillo de la Cueva y Piñar Mañas, El derecho a la autodeterminación informativa, 18.

23. Como señala la OC-CIDH, "los Estados deben respetar y garantizar a toda persona, la posibilidad de registrar y/o de cambiar, rectificar o adecuar su nombre y los demás componentes esenciales de su identidad como la imagen, o la referencia al sexo o género, sin interferencias por parte de las autoridades públicas o por parte de terceros. En esa línea, lo expresado implica necesariamente, que las personas que se identifiquen con identidades de género diversas deben ser reconocidas como tal". Cfr. Opinión Consultiva OC-24/17, párr. 115.

24. Cfr. Resolución de la Corte Constitucional 9, Registro Oficial 18, 3 de septiembre de 2009. Sentencia n. ${ }^{\circ}$ 019-09-SEP-CC. Caso: 0014-09-EP. 


\section{LOS DATOS SENSIBLES: CATEGORÍAS ESPECIALMENTE PROTEGIDAS SOBRE LA BASE DEL DERECHO A LA IDENTIDAD}

Líneas atrás, hemos desatacado una tipología de datos que corresponde a la esfera más íntima de la persona y que supone un régimen especial de garantía y protección. En efecto, se hace referencia a los datos sensibles. Este tipo de datos pertenece al ámbito íntimo de la persona y por consiguiente "es una información que se reserva para uno mismo o para los más cercanos y su conocimiento afecta gravemente a la intimidad personal y familiar y al libre desarrollo de la personalidad, teniendo un enorme potencial discriminador". ${ }^{25}$

En realidad, reforzando el criterio que describe el tipo de datos que se incluye en esta categoría, se considera aquella información personal "que revelan origen racial y étnico, opiniones públicas, convicciones religiosas, filosóficas o morales, afiliación sindical e información referente a la salud o a la vida sexual" ${ }^{26}$ Conviene subrayar que, bajo la condición de ocasionar un daño más grave a la dignidad humana y al libre desarrollo de la personalidad, "existen datos en apariencia inocuos o irrelevantes que, de modo súbito, se convierten en extremadamente sensibles mediante un sencillo cambio del fin que se persiguiera al momento de su recolección". ${ }^{27}$

Tal como señala la OC-CIDH, dentro esta categoría se enmarcan los datos relativos a la identidad de género. Al respecto, la resolución precisa que:

La falta de reconocimiento de la identidad de género o sexual podría resultar en una censura indirecta a las expresiones de género que se aparten de los estándares cisnormativos, o heteronormativos con lo cual se envía un mensaje generalizado de que aquellas personas que se aparten de dichos estándares "tradicionales" no contarán con la protección legal y el reconocimiento de sus derechos en igualdad de condiciones respecto de aquellas personas que no se aparten de los mismos. ${ }^{28}$

En este sentido, los datos personales pueden clasificarse según su mayor o menor relación con el concepto de dignidad y con el ejercicio de otros derechos fundamentales, como el respeto a la igualdad y no discriminación, por ejemplo. Así, bajo la categoría de datos sensibles, existe cierta información que no puede ser objeto de

25. Troncoso, La protección de datos personales: en busca del equilibrio, 782.

26. Víctor Bazán, "El hábeas data y el derecho a la autodeterminación informativa en perspectiva de Derecho Comparado", Estudios Constitucionales: Revista del Centro de Estudios Constitucionales, n. 2 (2005): 85-139.

27. Ibíd., 116.

28. Cfr. Opinión Consultiva OC-24/17, párr. 97. 
injerencia $u$ otras intromisiones por comprometer un alto grado de afectación a la dignidad, intimidad personal y familiar y al libre desarrollo de la personalidad. ${ }^{29}$

Precisamente, respecto a los datos de identidad de género, la OC-CIDH considera que "el derecho a la identidad se encuentra estrechamente relacionado con la dignidad humana, con el derecho a la vida privada y con el principio de autonomía de la persona". ${ }^{30} \mathrm{Al}$ describir el derecho a la identidad convicciones morales que se revelan a través del libre desarrollo de la personalidad, es importante considerar que esta tipología de datos afecta derechos relacionados con la igualdad y no discriminación. En efecto, la CCE advierte que "se reconoce el derecho que tienen todas las personas a vivir sin ser sometidos a cualquier forma de humillación, y gozar en condiciones de igualdad de los mismos derechos y obligaciones sin ningún tipo de discriminación". ${ }^{31}$

Por otra parte, hemos señalado que la garantía del derecho a la protección de datos personales se encuentra incardinada al hábeas data. Esta garantía permite no solamente ejercer los derechos relacionados con el control sobre el tratamiento de la información personal, sino también demandar mecanismos de protección que, en el caso de los datos sensibles, exige la adopción de medidas proactivas. Lógicamente, la garantía de estas facultades es esencial con el fin de fortalecer los principios de seguridad jurídica, confianza ciudadana y estricta legalidad en el Estado constitucional de derechos y justicia.

$\mathrm{Al}$ respecto, la OC-CIDH señala que:

Las medidas implementadas para hacer efectivo el derecho a la identidad no debe menoscabar el principio de seguridad jurídica. Este principio garantiza, entre otras cosas, estabilidad en las situaciones jurídicas y es parte fundamental de la confianza que la ciudadanía tiene en la institucionalidad democrática. Dicho principio se encuentra implícito en todos los artículos de la Convención. La falta de seguridad jurídica puede originarse por aspectos legales, administrativos o por prácticas estatales que reduzcan la confianza pública en las instituciones (judiciales, legislativas o ejecutivas) o en el goce de los derechos u obligaciones reconocidos a través de aquellas, e impliquen inestabilidad respecto del ejercicio de los derechos fundamentales, y de situaciones jurídicas en general. ${ }^{32}$

Por ello, si bien el derecho a la protección de datos reconoce el derecho a la decisión sobre información y datos de ese carácter, conviene destacar que es la garantía de hábeas data la que permite que el titular de la información personal pueda controlar

29. Cfr. Troncoso, La protección de datos personales: en busca del equilibrio, 781, 782.

30. Cfr. Opinión Consultiva OC-24/17, párr. 90.

31. Cfr. Resolución de la Corte Constitucional 184-18-SEP-CC, Caso n. ${ }^{\circ}$ 1692-12-EP.

32. Cfr. Opinión Consultiva OC-24/17, párr. 118. 
el tratamiento y finalidades sobre el uso de la información personal o datos sensibles como la identidad de género.

No obstante, en este fin es esencialmente importante el papel que desarrollan quienes se encargan del manejo y tratamiento de datos. Como señala la CCE, en lo que respecta al tratamiento de información, las instituciones públicas tienen la obligación de "velar por la exactitud y fidelidad de los datos registrados, sea en medio manual o informático, por la legalidad en su recolección, por el seguimiento y su constante actualización, por la implementación de dispositivos que impidan accesos no autorizados". ${ }^{33}$

En todo caso, nótese que, si bien la Corte hace referencia a la actividad de las instituciones públicas, en nuestro concepto este criterio es plenamente aplicable en todos los ámbitos puesto que el tratamiento inadecuado de datos sensibles puede ocurrir tanto en el ámbito público como privado. Por ello, no solamente es importante estimar las facultades de control que desarrolla el hábeas data, sino que, además, conviene abordar el problema del conocimiento y concienciación que se atribuye a quienes son responsables del tratamiento.

\section{EL (DES) CONOCIMIENTO SOBRE EL CONTROL DE LA INFORMACIÓN PERSONAL Y EJERCICIO DE LOS DERECHOS “ARCO”}

El derecho a la protección de datos se fundamenta en "garantizar a los ciudadanos unas facultades de información, acceso y control de los datos que le conciernen [...] en el seno de sus relaciones con los demás ciudadanos y con el poder público". ${ }^{34}$ Precisamente, uno de los principales problemas que enfrenta la protección de datos es el desconocimiento de este fundamento. Al respecto, la doctrina precisa:

El desconocimiento no es algo exclusivo de los ciudadanos. Se extiende a instituciones públicas y privadas que disponen de amplios volúmenes de información personal y, a veces, va acompañado por un escaso celo, cuando no despreocupación, en la aplicación de las normas legales y reglamentarias que la protegen..$^{35}$

33. Cfr. Resolución de la Corte Constitucional 9. Sentencia n. ${ }^{\circ}$ 019-09-SEP-CC.

34. Antonio Pérez Luño, Manual de informática y derecho (Madrid: Ariel, 1996), 44.

35. Pablo Lucas Murillo de la Cueva, "La protección de los datos de carácter personal en el horizonte de 2010”, Anuario de la Facultad de Derecho-Universidad de Alcalá, n. ${ }^{\circ} 2$ (2009): 131-42. 
Como sabemos, la garantía de este derecho implica no solamente la voluntad individual sino también un pacto colectivo. Desde el titular de los datos hasta quienes ejercen la responsabilidad de tratar información tienen la obligación de cumplir una serie de principios y deberes que merecen una necesaria aclaración con el objeto de garantizar integralmente el respeto de este derecho fundamental. Al respecto, la OCCIDH advierte:

La seguridad jurídica se ve garantizada -entre otras cosas- en tanto exista confianza en que los derechos y libertades fundamentales de todas las personas bajo la jurisdicción de un Estado parte de la Convención Americana serán respetados plenamente. Para el Tribunal, esto implica que la implementación de los procedimientos descritos a continuación, deben asegurar que los derechos y obligaciones respecto de terceros sean efectivamente tutelados sin que ello implique un menoscabo en la garantía plena del derecho a la identidad de género. ${ }^{36}$

Por ello, es importante centrar el debate en la preocupación sobre el desconocimiento del contenido de este derecho fundamental -sobre todo, en los datos relativos a la identidad de género- $y$ las facultades que se atribuyen a los titulares de la información personal. En todo caso, si bien "la protección de datos personales debe acompasarse atendiendo a la mayor o menor cercanía con otros derechos fundamentales", ${ }^{37}$ es fundamental conceptualizar las garantías que comporta el control de la información personal. Por ello, si queremos que en la práctica la Constitución se aplique como una regla de decisión conforme al principio de eficacia directa, la importancia del conocimiento de estas garantías es esencial para el principio y derecho a la seguridad jurídica. ${ }^{38}$

En este plano, nos referimos a las garantías que deben considerarse en el tratamiento de los datos relativos a la identidad de género. Por ejemplo, la confianza, la seguridad, la intimidad, la privacidad y confidencialidad constituyen presupuestos orientados a garantizar la igualdad y no discriminación a partir del tratamiento de datos. Así, con base al Estado constitucional de derechos es inexcusable que frente a contradicciones normativas o falta de ley no pueda aplicarse -por desconocimientode modo directo e inmediato las garantías que se desprenden del derecho a la protección de datos $\mathrm{y}$, en suma, de los datos relativos a la identidad de género.

36. Cfr. Opinión Consultiva OC-24/17, párr. 119.

37. Troncoso, La protección de datos personales: en busca del equilibrio, 781.

38. Como señala la OC-CIDH, si bien "los efectos de los referidos procedimientos son oponibles a terceros, los cambios, adecuaciones o rectificaciones de conformidad con la identidad de género no debe alterar la titularidad de los derechos y de las obligaciones jurídicas”. Cfr. Opinión Consultiva OC-24/17, párr. 119. 
Por otro lado, conviene precisar que la OC-CIDH dispone que los Estados "deberán desplegar sus esfuerzos para que las personas interesadas en que se reconozca su identidad de género auto-percibida en los registros, así como en los documentos de identidad, no tengan que emprender varios trámites ante una multiplicidad de autoridades".${ }^{39}$ Así, con el objeto de evitar multiplicidad de trámites, recordemos que el deber de los poderes públicos -extendido a los ciudadanos- exige la aplicación de la Constitución e instrumentos internacionales como una regla de decisión que garantice, en este caso, los derechos relativos a la protección de datos. No obstante, frente a su incumplimiento, el mecanismo jurisdiccional para exigir su justiciabilidad es el hábeas data que reconoce un conjunto de facultades destinadas a garantizar el ejercicio, control y poder de disposición de los datos personales a través de los derechos de acceso, rectificación, cancelación y oposición.

\section{Como señala la doctrina:}

El control del titular de los datos personales no es abstracto, sino concreto, con una capacidad real de informarse, exigir el consentimiento, acceder, rectificar, cancelar y oponerse al tratamiento de sus datos de carácter personal. Este derecho fundamental equivale a conocimiento y control. Este control se desarrolla en dos momentos: el primero, en la decisión de entregar los datos personales; el segundo, durante todo el tratamiento de los mismos a través de los derechos de acceso, oposición, rectificación y cancelación, que permiten seguir la vida del dato personal. ${ }^{40}$

Al concretarse los derechos de acceso, rectificación, cancelación y oposición dentro de la naturaleza del hábeas data, es preciso conceptualizar esta garantía con relación al procedimiento de adecuación integral de la identidad de género. Tomando en cuenta que el hábeas data se traduce como "un proceso constitucional o un recurso protectorio del derecho de autodeterminación informativa o derecho a la protección de los datos personales frente a posibles excesos del poder de registración precisamente de la información de carácter personal", ${ }^{41}$ la protección de datos sensibles relativos a la identidad de género se constituye como un recurso protectorio frente a los excesos del poder de registración, actualización o difusión de la información.

39. Cfr. Opinión Consultiva OC-24/17, párr. 124.

40. Troncoso, La protección de datos personales: en busca del equilibrio, 138.

41. Bazán, "El hábeas data y el derecho a la autodeterminación informativa en perspectiva de Derecho Comparado", 90 . 


\section{El hÁbEAS dATA COMO GaRANTÍA de CONTROL DE LOS DATOS DE CARÁCTER PERSONAL: EL PROCEDIMIENTO ENFOCADO A LA ADECUACIÓN INTEGRAL DE LA IDENTIDAD DE GÉNERO AUTOPERCIBIDA}

Las garantías constitucionales consisten en mecanismos de protección jurídica que disponen los ciudadanos para tutelar y asegurar el cumplimiento de los distintos derechos fundamentales que se consagran en la Constitución e instrumentos internacionales de derechos humanos. Así, como señala la doctrina, "la idea de las garantías es establecer mecanismos para prevenir y reparar las violaciones de derechos que se puedan producir por cualquier acto u omisión del estado o de sujetos con poder". ${ }^{42}$

Es de apreciación generalizada que el problema de las garantías no está en su fundamento ni en el reconocimiento de los Estados en el ordenamiento jurídico. El principal problema al que se enfrentan es su tutela y su ejercicio en la práctica.

Sobre el tema que nos ocupa, el problema del reconocimiento de los derechos vinculados a la identidad de género en el caso "Satya" en Ecuador tuvo una evidente limitación de libertades relacionadas con la protección de datos sensibles. La CCE fue enfática en considerar que para la tutela de la identidad y del desarrollo integral de los derechos de la personalidad, las entidades públicas deben "desvirtuar toda clase de barreras que impidan materializar los derechos en condiciones de una adecuada infancia, así como toda etapa de desarrollo posterior" ${ }^{43}$ En este mismo sentido coindice la OC-CIDH al considerar que:

Es una obligación del Estado asegurarse de que las modificaciones sobre los datos de la persona que se perfeccionen ante los registros civiles sean actualizadas en los demás documentos e instituciones a que haya lugar sin que se requiera la intervención del requirente, de manera que no se someta a esa persona a cargas irrazonables para que la adecuación de su identidad de género auto-percibida tenga vigencia en todos los registros que sean relevantes para tales efectos. ${ }^{44}$

42. Ramiro Ávila Santamaría, Los derechos y sus garantías. Ensayos críticos (Quito: Corte Constitucional para el Período de Transición, 2012), 187.

43. La Corte agrega que "la entidad pública, frente a su deber de garantía del derecho constitucional de niños y niñas a tener identidad, nombre y ciudadanía, estuvo obligada a emplear en forma preferente el principio del interés superior del niño en armonía con el principio de trato prioritario a fin de sobreponer el efectivo goce de los derechos de Satya Amani por sobre cualquier otra consideración en atención a la satisfacción de sus necesidades primordiales". Cfr. Resolución de la Corte Constitucional 184-18-SEP-CC, Caso n. ${ }^{\circ}$ 1692-12-EP.

44. Cfr. Opinión Consultiva OC-24/17, párr. 124. 
Frente a esta realidad, las garantías constitucionales suponen mecanismos jurisdiccionales de tutela bajo las cuales "todos los poderes del estado y los funcionarios y funcionarias que lo representan y conforman son garantes de los derechos humanos y de la naturaleza". ${ }^{45}$ Desde esta perspectiva, la garantía de los derechos enfrenta nuevas realidades e importantes desafíos. Como se ha expuesto, un nuevo paradigma representa la garantía del derecho a la protección de datos. Más aún, si se hace referencia a la tutela de datos sensibles relativos a la identidad de género por cuanto, como señala la doctrina, "tales datos merecen una garantía reforzada, para evitar decisiones discriminatorias o especialmente perjudiciales para sus titulares". ${ }^{46}$

En todo caso, la Corte Constitucional expone que:

Se subraya, además, la necesidad de armonizar las disposiciones contenidas en el ordenamiento jurídico ecuatoriano a fin que su aplicación guarde correspondencia con los preceptos constitucionales, en tanto la norma suprema del Estado brinda seguridad jurídica a todas las personas quienes se ven amparadas por el pacto constitucional dispuesto democráticamente para la tutela de sus derechos. ${ }^{47}$

Ciertamente, hay que posibilitar un sistema armónico y equilibrado de protección de los derechos fundamentales sobre la base del Estado constitucional de derechos. Naturalmente, en materia de datos sensibles, "todo este sistema garantista presupone para su eficaz ejercicio el reconocimiento del habeas data, ya que sin la previa posibilidad del acceso a los datos sería inviable el ejercicio de todo el ulterior sistema de garantías y derechos". ${ }^{48}$ Como advierte la OC-CIDH, el procedimiento enfocado a la adecuación integral de la identidad de género exige que:

Los Estados deben respetar la integridad física y psíquica de las personas reconociendo legalmente la identidad de género auto-percibida sin que existan obstáculos o requisitos abusivos que puedan constituir violaciones a los derechos humanos. Desde esta perspectiva, esos órganos recomiendan que el proceso de reconocimiento de la identidad de género no debe imponer a los solicitantes el cumplimiento de requisitos abusivos tales como la presentación de certificaciones médicas o pruebas de estado civil de no casados. ${ }^{49}$

45. Ávila Santamaría, Los derechos y sus garantías. Ensayos críticos, 188.

46. Enrique Pérez-Luño Robledo, El procedimiento de Hábeas Data: el derecho procesal ante las nuevas tecnologías (Madrid: Dykinson, 2017), 228.

47. Cfr. Resolución de la Corte Constitucional 184-18-SEP-CC, Caso n. ${ }^{\circ} 1692-12-E P$.

48. Pérez-Luño Robledo, El procedimiento de Hábeas Data: el derecho procesal ante las nuevas tecnologías, 220.

49. Cfr. Opinión Consultiva OC-24/17, párr. 129. 
Si bien el hábeas data tradicionalmente se asocia como una garantía que permite el conocimiento y/o acceso de la información personal, en la actualidad esta garantía se orienta a proteger los derechos de los ciudadanos frente al tratamiento ilícito de la información, y que esencialmente "hace referencia al conjunto de los denominados derechos o facultades ARCO, es decir, a los derechos de Acceso, Rectificación, Cancelación y Oposición. Estas facultades conjuntamente constituyen el núcleo del derecho a la libertad informática o derecho de autodeterminación informativa". ${ }^{50}$

Bajo estas consideraciones, nos parece importante aclarar brevemente el contenido que, según la doctrina, desarrolla el hábeas data con el objeto de enfocar el procedimiento adecuado en el tratamiento de información relativa a la identidad de género.

Por ejemplo, Gozaíni refiere que el hábeas data se afirma en la defensa "de la privacidad, o de la dignidad humana, o el derecho a la información, o bien la tutela del honor, o de la propia imagen o perfil personal, o derecho a la identidad, o simplemente acotado a la autodeterminación informativa". ${ }^{51}$ Se concibe como un mecanismo de garantía con carácter instrumental, por cuanto, si bien garantiza el control sobre el tratamiento de la información personal, debe recordarse que también protege otros derechos derivados de la autodeterminación informativa, como los relativos a la identidad de género.

Así, también Pérez Luño advierte que esta garantía se fundamenta en el "interés de las personas concernidas para tener acceso a los datos personales que les afecta. De ahí la posibilidad de ordenar el acceso a los registros o archivos de datos para constatar la autenticidad o corrección de lo expresado". ${ }^{52} \mathrm{Al}$ caso, Puccinelli agrega:

El hábeas data o protección de datos personales, establece garantías mínimas de calidad y confiabilidad de los datos nominativos o personales que se recojan; el derecho de las personas a exigir que sus datos personales le sean exhibidos; el derecho a que sean rectificados y el derecho a excluir los datos privados mantenidos sin autorización. ${ }^{53}$

En consecuencia, el hábeas data constituye una garantía respecto al derecho a la autodeterminación informativa, frente al uso ilícito, disposición arbitraria, desigualdad y discriminación de la cual puede ser objeto la información relativa a la identidad

50. Pérez-Luño Robledo, El procedimiento de Hábeas Data: el derecho procesal ante las nuevas tecnologías, 115.

51. Osvaldo Gozaíni, Derecho procesal constitucional: Hábeas Data-Protección de datos personales (Buenos Aires: Rubinzal-Culzoni Editores, 2001), 13.

52. Pérez-Luño Robledo, El procedimiento de Hábeas Data: el derecho procesal ante las nuevas tecnologías, 114.

53. Oscar Puccinelli, El Hábeas Data en Indoiberoamérica (Santa Fe de Bogotá: Temis S.A., 1999), 351. 
de género. Ahora bien, como señala la Constitución, el hábeas data frente al tratamiento de datos sensibles exige "la adopción de las medidas de seguridad necesarias".

Precisamente, la doctrina afirma que esta garantía permite que el titular de la información personal se pueda informar "con qué garantías está almacenando esas informaciones y qué aplicaciones tecnológicas usa para conservar adecuadamente la información; es decir, qué seguridades ofrece el titular del archivo o base de datos para prevenir daños, manipulaciones o usos indebidos de los mismos". ${ }^{54}$ A esto se añade que "la tarea de control de la existencia y funcionamiento de los bancos de datos, no solo debe quedar en manos del poder político [...] sino que debe recaer también en los particulares". ${ }^{55}$

Tal como señala la OC-CIDH:

El carácter reservado de los procedimientos de cambio del nombre de pila y en su caso, género o sexo e imagen de acuerdo a la identidad de género auto-percibida, se encuentran en armonía con lo dispuesto por los principios de Yogyakarta cuando estos estipulan que todas las personas, con independencia de su orientación sexual o identidad de género, tienen el derecho a la vida privada, sin injerencias arbitrarias o ilegales en la misma, esto incluye el derecho a optar por revelar o no la propia orientación sexual o identidad de género. ${ }^{56}$

Sobre esta base, en una sociedad moderna, debemos considerar que el tratamiento de la información personal exige la adopción de medidas proactivas que previenen desde el diseño y por defecto la protección de la intimidad y privacidad de datos personales. Esto es lo que la doctrina denomina como principio de responsabilidad proactiva o demostrada. La cuestión se vuelve más importante si se trata de información sensible relativa a la identidad de género. Por ello, en el ejercicio de las actuaciones administrativas, los procedimientos de adecuación de datos conforme a los ámbitos ligados con el desarrollo de la personalidad merecen especial atención y protección con el objeto de garantizar seguridad jurídica del instituto de garantía que comprende el derecho a la protección de datos.

54. Pérez-Luño Robledo, El procedimiento de Hábeas Data: el derecho procesal ante las nuevas tecnologías, 23.

55. Luis Castillo Córdova, Hábeas Corpus, Amparo y Hábeas data (Lima: ARA, 2003), 371.

56. Cfr. Opinión Consultiva OC-24/17, párr. 138. 


\section{CONCLUSIONES}

El derecho a la protección de datos personales, el derecho a la identidad de género y la garantía de hábeas data tienen un elemento instrumental que, a través del denominado instituto de garantía de otros derechos fundamentales, desarrolla una protección de libertades vinculadas con el libre desarrollo de la personalidad, igualdad y no discriminación. Atribuyen, con base al principio de eficacia directa, protección constitucional no solamente frente al tratamiento de cualquier tipo de información sino, además, sobre aquella que se considera como sensible o especialmente protegida.

En el marco del Estado constitucional de derechos y justicia, la exigibilidad y el reconocimiento de los datos de conformidad con la identidad de género tienen origen en el respeto de las garantías previstas para el derecho a la protección de datos y hábeas data reconocidas en la Constitución e instrumentos internacionales como la Opinión consultiva OC-24/17. Esto demanda de los poderes públicos y también particulares -bajo el principio de eficacia directa y seguridad jurídica- observar el cumplimiento de una serie de principios, entre ellos el de secreto, de seguridad y de confidencialidad de los datos relativos a la identidad de género. Por ello, Estado y sociedad tenemos el imperativo de reconocer el carácter normativo superior de la Constitución bajo el cual los datos personales no pueden utilizarse para fines que promuevan la desigualdad y/o discriminación en razón de la identidad de género.

\section{BIBLIOGRAFÍA}

Ávila Santamaría, Ramiro. Los derechos y sus garantías. Ensayos críticos. Quito: Corte Constitucional para el Período de Transición, 2012.

Bazán, Víctor. "El hábeas data y el derecho a la autodeterminación informativa en perspectiva de Derecho Comparado". Estudios Constitucionales: Revista del Centro de Estudios Constitucionales, $\mathrm{n}^{\circ} 2$ (2005): 85-139.

Corte Interamericana de Derechos Humanos. Opinión consultiva OC-24/17 relativa a la identidad de género, e igualdad y no discriminación a parejas del mismo sexo, 2017.

Gozaíni, Osvaldo. Derecho procesal constitucional: Hábeas Data-Protección de datos personales. Buenos Aires: Rubinzal-Culzoni Editores, 2001.

Murillo de la Cueva, Pablo Lucas. "La protección de los datos de carácter personal en el horizonte de 2010". Anuario de la Facultad de Derecho-Universidad de Alcalá, n. 2 (2009): $131-42$.

Murillo de la Cueva, Pablo Lucas, y José Luis Piñar Mañas. El derecho a la autodeterminación informativa. Madrid-México: Fontamara, 2011.

Nikken, Pedro, "Sobre el concepto de Derechos Humanos", en Instituto Interamericano de Derechos Humanos, Seminario de Derechos Humanos. San José, Costa Rica: IIDH, 1997. 
Ordóñez Pineda, Luis. "La protección de datos personales en los Estados que conforman la Comunidad Andina: estudio comparado y precisiones para un modelo interamericano de integración". Foro: Revista de Derecho, n. ${ }^{\text {o }} 27$ (2018).

Oró Badia, Ramón. La protección de datos. Barcelona: UOC, 2015.

Pérez Luño, Antonio. Manual de informática y derecho. Madrid: Ariel, 1996.

Pérez-Luño Robledo, Enrique. El procedimiento de Hábeas Data: el derecho procesal ante las nuevas tecnologías. Madrid: Dykinson, 2017.

Puccinelli, Oscar. El Hábeas Data en Indoiberoamérica. Santa Fe de Bogotá: Temis S. A., 1999.

Troncoso, Antonio. La protección de datos personales: en busca del equilibrio. Valencia: Tirant lo Blanch, 2010. 